\title{
A Study on the Perception of Personal Mobility Vehicle for the Improvement of Pedestrian Environment for the Disabled
}

\author{
Joohyung Lee ${ }^{a}$, Kyooil Lee ${ }^{b}(\mathbb{0}$ \\ aVice Director, Seoul Universal Design Center, Seoul, Republic of Korea \\ ${ }^{\mathbf{b}}$ Department of Architecture, College of Culture and Arts, Sahmyook University, Republic of Korea
}

Objective: In order to secure the right to walk for the weak, such as the disabled, this study aims to suggest ways to improve the pedestrian environment by identifying factors that cause obstacles to walking.

Design: Data Analysis and Perception Survey.

Methods: The questionnaire was conducted separately between users of personal mobility vehicle and non-users. A total of 207 effective questionnaires were collected, and the analysis analyzed the perception of personal mobility vehicle by conducting frequency analysis using SAS 9.4. The survey focused on basic information on respondents, walking conditions, understanding of personal mobility vehicle, awareness of pedestrian space passage and parking, and awareness of the possibility of securing pedestrian rights due to new regulations.

Results: First, when moving a pedestrian path by personal mobility vehicle, it shall be limited to less than the walking speed of pedestrians. Second, the parking location of the personal mobility vehicle is located at the boundary of the pedestrian road and the lane. Third, pay a fair price to park in a pedestrian space.

Conclusions: It is necessary to improve the system to strengthen the contents of education to take into account the safety of pedestrians in education on how to use personal mobility vehicle.

Key Words: Personal Mobility Vehicle, Pedestrian Environment, the Handicapped, Road Organization

서론

최근 스마트 시티, 공유경제 등의 흐름에 따라 스마트 모빌리티(Smart Mobility)에 대한 중요성이 부각되고 있고, 이와 더불어 전동 킥보드와 같은 개인형 이동수단(Personal Mobility) 산업이 크게 성장하고 있는 추세이다. 교통연구 원[1]에 따르면 국내 개인형 이동수단 시장은 2016년 6만 대, 2017년 7.5만대, 2018년 9만대로 연평균 $20 \%$ 이상 고속성장중이며, 2022년에는 20만대까지 증가할 것으로 예측하고 있다.

다양한 개인형 이동수단이 이용되고 새로운 대체 교통 수단이 활성화되고 있는 현실에서 기존의 도시와 도로의 구조는 이러한 변화의 속도를 맞추어 나가지 못하고 있다. 새로운 개인형 이동수단이 대량으로 공급되고 이용됨으로
인해 기존 보행자 공간의 침범, 개인형 이동수단의 무분 별한 주차 등 보행권을 침해하는 문제가 크게 대두되고 있는 실정이다. 특히, 이동수단의 이용자가 보도 위에 무 분별하게 주차함에 따라 보행의 방해요소로 작용되고 있 으나 이를 제재할 수 있는 관련 법규 또한 모호하여 지자 체가 부적절한 주차에 대해 과태료를 부과하거나 단속할 수 없는 실정으로 지자체별 이에 대한 대응 방안을 모색 중에 있다. 또한 개인 사유공간 내 불법 주차 등으로 인해 일부 사업자는 건물주 등과 협의하여 주차공간을 확보하 고자 하는 노력을 보이고 있으나 이 또한 쉽지 않는 상황 이다. 도시와 도로의 구조가 새로운 교통수단에 대하여 빠르게 대응하지 못하는 동안 기존의 보행환경은 매우 열 악해지고 있으며 이에 따른 안전사고도 증가하고 있다. 특히 보행에 어려움이 있는 노인이나 휠체어사용자와 같

Received: May 17, 2021 Revised: May 26, 2021 Accepted: May 27, 2021 Corresponding author: Kyooil Lee(ORCID https://orcid.org/0000-0003-4765-2586) Department of Architecture, College of Culture and Arts, Sahmyook University Hwarangro 815, Seoul 01795 Republic of Korea

Tel: + 82-2-3399-1854 Fax: + 82-2-3399-1857 E-mail: kilee@syu.ac.kr

This is an Open-Access article distributed under the terms of the Creative Commons Attribution Non-Commercial License (http://creativecommons.org/licenses/ by-nc/4.0) which permits unrestricted non-commercial use, distribution, and reproduction in any medium, provided the original work is properly cited. Copyright $(2021$ Korean Academy of Physical Therapy Rehabilitation Science 
은 교통약자들에게는 단순히 보행환경이 악화되는 정도가 아닌 일상생활 및 사회참여의 불가능 문제와도 연결되는 심각한 장애물이라고 할 수 있다.

이와 같은 사회 변화에 대응하여 최근 국내외에서는 교 통약자를 포함한 누구나 도시환경을 공평하게 이용하며 모든 사용자의 요구를 충족해줄 수 있도록 보편적 디자인 (Universal Design)에 대한 관심이 높아지고 있다. 국외의 경우 차별 없는 도시 및 보행공간 이용성 보장을 위하여 유니버설디자인을 적극적으로 도입하고 있는 상황이다. 일본의 경우 2020년 올림픽 및 패럴림픽 개최를 염두에 두고 공생사회 만들기를 목표로 도시, 교통, 보행공간을 정비하여 왔다. 노르웨이의 경우에는 노르웨이 유니버설 디자인 2025 등 중앙정부를 중심으로 각 단계별 5 개년의 행동계획을 수립하여 도시·건축·교통 등의 물리적 환경 뿐만 아니라 제도, 산업, 일자리, 교육, IT 분야 등 국가의 전 분야에 걸쳐 평등하고 보편적인 개념이 적용되도록 하 고 있다. 이와 같이 모두에게 접근 가능한 공공공간, 교통, 보행공간을 제공하고자 정책을 수립하고 계획하고 정비하 는 것처럼 우리나라도 정책 마련이 시급하다.

이에 본 연구는 장애인 등 교통약자의 보행권을 확보하 고 보행자와 상충되는 문제를 해소할 수 있도록 개인형 이동수단에 대한 인식조사 분석을 통해 보행에 장애가 되 는 요소를 파악함으로써 보행환경 개선 방안을 제시하여 정책수단 마련의 기초자료로 제공하고자 한다.

\section{연구 방법}

본 연구는 서울시의 개인형 이동수단의 보행장애 요소 를 현황조사를 통해 도출하고 개인형 이동수단의 이용자 및 비이용자의 의견조사를 바탕으로 보행환경의 개선방안 을 제언하고자 하며 본 연구의 방법은 다음과 같다.

먼저 국내외 개인형 이동수단과 관련된 정책 및 제도에 대한 문헌고찰을 통해 주요 개념 정리와 국내 제도의 한 계점을 파악한다. 이어서 개인형 이동수단의 이용자 및 비이용자를 대상으로 한 인식조사를 통해 개인형 이동수 단의 규제를 포함하여 교통약자의 보행환경 개선을 위한 방안을 도출한다. 본 연구에서는 전동킥보드와 같은 개인 형 이동수단을 자전거도로를 이용하는 개인형 이동장치라 는 위계로 설정하여 보행에 장애가 되는 요소를 파악함으 로써 보행공간에서의 교통약자 보행권 확보 방안을 모색 해 보고자 한다.

\section{이론적 고찰}

\section{개인형 이동수단의 정의}

개인형 이동수단은 명확히 정의 내리기 어려우나, 대체로
‘퍼스트마일/라스트마일(First Mile/Last Mile)' 구간을 이동 하는 1 2인승 소형 개인 이동수단으로 정의될 수 있다. 미국, 싱가포르 등 국외의 경우 관련 법률(「교통법」(Vehicle Code), 「액티브 모빌리티법 (Active Mobility Act) 등)에 개인형 이동수단의 정의와 운행사항을 정비하여 안전한 운행을 도모하고 있다. 이에 반해 한국은 개인형 이동수 단의 법적 정의가 규정되어 있지 않고, 특히 보행환경 내 의 주차 공간 및 보행자와의 위계 등이 설정되어 있지 않 아 이에 대한 대책 마련이 필요한 상황이다. 전동킥보드, 전동휠 등 개인형 이동수단은 현행「도로교통법」상 '이 륜자동차' 또는 '원동기장치자전거'에 해당되어 보도와 자 전거 전용도로를 이용하지 못하게 되어 있으나, 대부분의 이용자는 보도를 이용하고 있는 상황이며, 이에 대한 법적 위계설정이 필요한 상황이다. 다행히 20 대 국회에서「도 로교통법 일부 개정을 통해 자전거도로의 이용 가능에 대한 지위를 부여하고 있으나, 보행공간내의 이용과 무분 별한 주차 문제 등은 여전히 제도 및 정책적으로 해결해 야 할 문제이다.

2020년 6월 현재까지 법원의 판례를 살펴보면 전동킥 보드 등의 개인형 이동수단은 「도로교통법」제 2 조 제 19 호에 따른 원동기장치자전거로 간주되고 있다. 주요 판결 의 판시에 따르면 전동킥보드는「도로교통법」상 '원동기 장치자전거'로 분류되고, 전동킥보드 운전자는 음주운전 등「도로교통법」상 각종 규제에 대하여 자동차 및 오토바 이 운전자와 동일한 의무를 부담하여야 한다고 되어 있다. 이에 따라 전동킥보드 운전자는 차도로 다녀야 하며 자전 거 도로와 인도에서 달릴 수 없다. 또한 전동킥보드를 타 기 위해서는 2 종 원동기장치자전거 이상의 운전면허가 필 요하며 운행자격이 없는 16 세 미만의 미성년자는 전동킥 보드를 운전할 수 없고,「도로교통법」상 운전자에 대한 각종 규제 및 벌칙도 동일하게 적용된다. 다만, 위 판례의 내용은 ‘원동기장치자전거’라는 과거의 법적 개념을 새롭 게 등장한 개인형 이동수단에 일률적으로 적용한 것으로 변화된 교통 상황에 적합한지에 대해서는 많은 논란이 존 재한다. 법률 체계상 차도를 이용해야 하지만 이용 위험 성이 존재하고, 보행공간 이용 역시 보행자에게 위협이 되므로 자전거도로의 사용을 유도할 필요가 있으나, 법률 적 정비가 미비하여 현실적으로 많은 모순이 존재한다.

이러한 논란 속에서 20 대 국회 말기에「도로교통법 중 일부를 개정하여 개인형 이동수단에 대한 법적 지위를 명시하고 있다. 개정 법률안에 따르면 기존의 원동기장치 자전거에 속하던 개인형 이동수단의 법적지위를 '자전거 및 개인형 이동장치'로 속하게 하여 자전거도로 등의 이 용이 가능하도록 하였다. 이와 함께 '개인형 이동장치'에 대하여 '원동기장치자전거' 중 시속 25 킬로미터 이상으로 운행할 경우 전동기가 작동하지 아니하고 차체 중량이 30 
킬로그램 미만인 것으로서 행정안전부령으로 정하는 것으 로 정의하고 있다. '원동기장치자전거'에 대해서도 「자동 차관리법」 제 3 조에 따른 이륜자동차 가운데 배기량 125 시시 이하(전동기를 동력으로 하는 경우에는 최고정격출 력 11 킬로와트 이하)의 원동기를 단 차로 발전하는 교통 수단 기술력을 반영하여 정의하고 있다. 결론적으로 기존의 개인형 이동수단을 '자전거 등'에 포함시켜 자전거 도로 이용 등 관련 법적 테두리에 포함시키도록 하였고, ‘자동 차 등'에 포함되었던 법적지위를 '자동차 등(개인형 이동 장치는 제외한다)'에서 제외시켜 법적 체계를 정비하였다.

\section{국내 개인형 이동수단의 서비스 현황}

공유형 공공이동수단인 따릉이의 경우 2010년 11월에 서 2015년까지 시범적으로 운영하였고, 이후 확대 운영을 거쳐 현재에 이르고 있다. 이러한 과정에서 '따릉이' 브랜 드 개발 및 관련 디자인이 개발되어 2018년 1월 기준 16,000 대의 자전거와 1,044 개소의 대여소, 13,247 개의 거 치대를 운영중에 있다. 이와 같이 확대 운영 중인 공공자 전거의 사고현황을 살펴보면 2016년 61건(전체 이용대비 $0.004 \%$ ), 2017년 285건(전체 이용대비 $0.006 \%$ ) 등 이용 대비 비율은 미약하지만 발생건수 자체는 점차 증가하고 있는 추세에 있다.

국내 공유 전동킥보드의 경우 약 20 여 곳에서 공유서 비스를 제공하고 있다[1]. 대표적인 공유 전동킥보드 서비 스 현황은 다음과 같으며, 각 운영사별 관련 투자 유치 및 사업 확장 계획 등을 고려하여 향후 2 만 대 이상으로 증 가할 것으로 예측하고 있다.

\section{국내 개인형 이동수단 관련 정책 및 안전기준}

국내국내 공유 전동킥보드의 경우 신생 스타트업뿐만 아니라 국외 리딩 업체의 서비스가 본격적으로 시작되고 있으며, 현대 자동차와 같은 완성차 업체에서도 시장에 진입하고 있다. 관련 산업의 발달 및 규모가 증가함에 따 라 보행 공간 침범, 무분별한 거치 등으로 보행자의 보행 권 침해 등 많은 문제가 대두되고 있는 실정이다. 특히, 이용자가 보도위에 무분별하게 주차함에 따라 보행의 방 해요소로 작용되나 관련 법규가 모호하여 지자체가 부적 절한 주차에 대한 과태료를 부과하거나 단속할 수 없는 실정으로 지자체별 이에 대한 대응 방안을 모색 중에 있 다. 또한 개인 사유공간 내 불법 주차 등으로 인해 일부 사업자는 건물주 등과 협의하여 주차공간을 확보하고자 하는 노력을 보이고 있으나 쉽지 않는 상황이다.

서울시의 경우 지난 5 월 전동킥보드를 원동기장치자전 거로 분류하여 불법 주차시 이용자에게 과태료와 견인 처 리 비용을 부과하는 방안을 추진 중이었으나, 기존 전동
킥보드를 자전거 등으로 분류한 20대 국회 말기 가결된 「도로교통법」 개정안으로 인해 관련 정책 시행에 많은 논 란이 있다. 다만 개정된 법률에서도 주차 문제에 대해서 는 여전히 제도적 장치가 미흡한 상황으로 이에 대해서는 많은 논의가 필요해 보인다. 서울시의 경우 자전거의 경 우 불법 주정차시 견인을 하지 않고 있어 관련 업계에서 는 많은 반발 의견을 제시하고 있다. 서울시와 관련 업계 의 업무 협약에서는 인도 중앙, 건물 출입구, 건널목 진입 로, 소방시설 인근 등에 주차시 업체 공동으로 킥보드를 수거하여 재배치하는 방향으로 타협하였으나, 서울시는 이와 동시에 견인비 부과라는 조례 개정도 추진하고 있다.

종로구와 부산 수영 - 해운대구의 경우는 불법 주정차된 전동 킥보드를 수거하여 이와 관련된 비용을 과태료 형식 으로 부과하게 하고 있다. 현행 법률상 불법주정차 단속 대상이 아니므로 견인에 따른 비용 청구로 우회징수토록 하고 있다.

서초구의 경우에는 2020년 2월 전국 최초로 킥보드 전 용 주차장을 조성하여 전동킥보드의 무질서한 주차를 예 방하고 안전한 보행환경을 조성하고자 하고 있다. 관내 지하철역 주변에 보행에 방해가 되지 않는 위치에 일정 구역에 위치표기를 통해 조성하였다. 이와 더불어 자전거 거치대 50 곳에 전동킥보드 주차를 시범적으로 허용하고 있으며, 동시에 혼잡지역 50곳은 전동킥보드 주차금지 구 역(횡단보도 진입로, 지하철역, 버스정류장 주변 등)으로 지정하고, 노면에 주차금지 표시를 하고 있다.

현재 문제가 되고 있는 전동킥보드 등의 개인형 이동수 단은「전기용품 및 생활용품 안전관리법」(약칭: 전기생활 용품안전법, 전안법) 제 15 조 제 3 항(안전확인대상제품의 신고 등), 「안전확인대상생활용품의 안전기준」 제 2 조(안 전기준) 제2항의 부속서 40(이륜자전거)와 부속서 72(전 동보드)에 따라 품질 및 안전인증/확인을 받아야 한다.

이 중 전동킥보드에 대한 주요 안전기준을 살펴보면 다 음과 같다. 최대 무게는 배터리를 포함하여 $30 \mathrm{~kg}$ 미만이 어야 하며, 안전 운행을 위한 전조등, 미등, 측면 반사경 과 경음기 등이 부착되어야 한다고 규정하고 있다. 운행 과 관련하여서는 브레이크 설치, 최대속도 $25 \mathrm{~km} / \mathrm{h}$ 이하, 제동거리 $5 \mathrm{~m}$ 이하, 외부 환경에서의 원활한 작동을 고려 한 방수, 저·고온 시험, 배터리 성능 및 1 회 충전 거리 등을 규정하고 있고, 헬멧 등의 안전보호장구 착용, 급제 동시의 전복위험, 차도나 교통이 혼잡한 곳과 급경사지 등 위험지역에서의 운행 제한 및 자제에 대한 경고 문구 를 표시하도록 하고 있다. 이전의 기준에 비해 교통수단 으로써 도로 운행을 위한 주행 안전기준 항목이 추가되고, 기존의 스케이트보드 내의 종류로 포함시켜 안전 확인을 받던 규정을 별도의 부속서를 제정하여 관리하고 있어 안 전기준을 강화하고 있는 상황이다. 하지만 전동킥보드 중 
Table 1. Domestic Safety Standards for Personal Mobility

\begin{tabular}{lll}
\hline Sortation & Content & \\
\hline \multirow{3}{*}{ appearance } & Maximum Weight & Less than $30 \mathrm{~kg}$ with battery \\
& Headlights, taillight & Fixed headlights, taillight or rear reflector \\
& Side Reflector & Two-sided reflector or reflector attachment \\
& Horn & Attach Horn \\
\hline \multirow{2}{*}{ Operational Related } & Attachment brakes, speed limit (25 km/h or less), braking distance (5 m or less), waterproof \\
& and cold/high temperature tests, batteries, etc. \\
\hline \multirow{2}{*}{ Display points } & Wearing safety protective equipment, such as helmets, indicating the danger of overturning \\
& when braking suddenly, restricting the operation of roads or congested areas, etc. \\
\hline
\end{tabular}

Source of Data: Korean Agency for Technology and Standards, Safety Verification Safety Standards Annex 72 (Electric Personal Mobility)

안장이 부착된 전동킥보드 등 일부 제품은 안전 확인 대 상제품에 해당하지 않아 관리의 사각지대에 놓인 것들이 존재하고 있다.

해당 안전기준은 2019년 11월 15일 제정(국가기술표 준원고시 제2019-0387호)되어 2020년 2월 16일 시행되 었고, 이후 수입 및 공급되는 제품에만 적용되고 있으며, 해당 시점 이전의 안전확인을 받은 이동장치는 교통수단 으로써의 안전기준(조향장치, 조명, 미등, 반사장치, 제동 거리, 제한속도 등)을 준수하지 못한 경우가 있다. 전동킥 보드 등의 이동수단 이용이 급증하고 있는 상황에서 강화 된 안전기준의 수립 및 적용은 바람직하나, 이미 적합확 인을 받고 운행중인 수천 수만대의 이동수단에 대한 안 전규제는 미흡한 상황이다.

\section{국외 개인형 이동수단 관련 정책 및 안전기준}

미국은 2017년 6 9월 산타모니카에서 버드(Bird)가 최초로 공유 전동킥보드 서비스를 개시하였으며[2], 이후 급속히 증가하여 2018년 말 미국 내 다수의 도시에서 서 비스가 제공되고 있다. 공유 전동킥보드 사업은 허가 대 상 사업이 아니므로 해당 도시와의 허가나 협의 없이 사 업자가 일방적으로 서비스를 게시하고 있으며, 이로 인해 지역 내 공유 킥보드 장치와 서비스 업체의 과도한 밀집, 그에 따른 전용도로 및 주차공간 문제 등 많은 문제가 나 타났다. 이러한 문제 대응을 위해 일부 도시들은 서비스 제한, 벌금 부과 등의 규제로 대응하고 있으며, 샌프란시 스코, 포틀랜드 등의 도시에서는 시범사업을 시행하여 적 절한 규제와 산업 진흥 방안을 모색하고 있다[3].

미국의 공유 전동킥보드 서비스의 경우 신규 스타트업 뿐만 아니라 기존 완성차 업체, 공유차량 업체 등 다양한 분야의 업체들이 시장에 진입하고 있으며, 산업의 규모와 이용자가 증가하고 있는 상황이다. 이러한 서비스 시장의
성장과 더불어 국내에서 대두되고 있는 것과 마찬가지로 개인형 이동수단의 무분별한 주차 문제 및 보행공간 침범 문제가 존재하며, 이에 대한 사회적 논의가 활발히 진행 중에 있다.

미국은 교통약자의 가장 기본적인 접근과 이동공간이 라 할 수 있는 도시 내 연석 및 경사로 구간이 현재 다양 한 공유 이동수단의 이용을 위한 경쟁 구간이 되었으며, 교통약자의 보행권 보장을 위해 몇몇 도시에서는 연석 구 간 관리에 대한 정책 개발과 운영 방안을 모색하고 있다. 다수의 공공 기관 및 지방정부에서 공유 이동수단의 해당 연석 구간 이용에 대해 이용요금을 부과하고 있다. 요금 은 이동수단 기기당, 일/월/연간 이용 형태로 서비스 운영 사에 부과하고 있다. 또한 용량을 제한하는 방안을 모색 중인데, 연석 구간 등에는 일정 대수 이상의 이용과 주차 가 되지 않도록 이동수단의 운영 대수를 조절하고 있다. 특히, 대여소나 정류소 장치가 없는 형태의 공유 이동수 단의 경우 운영 및 이용 대수를 운영사별로 제한시키고 있다. 아울러 다수의 도시에서 개인형 공유 이동수단을 위한 지정 주차구역 정책을 시행하고 있다. 지정 주차구 역은 노외 주차공간과 같은 연석 구간, 스트리트 퍼니쳐 와 같은 대여/정류소, 또는 바닥면의 표시구간 등을 포함 하고 있다[4].

국외 개인교통수단의 성능 및 안전요구 사항은 국가 및 도시의 교통시스템이나 상황에 따라 다르게 규정하고 있 다. 크게 도로의 이용을 허가하는 경우와 그렇지 못한 경 우로 나눌 수 있다. 또한 차로나 자전거 도로 이용 상황에 따라 국가 및 도시 별로도 요구하는 성능과 안전기준이 상이하다. 국가 및 도시별로 안전과 관련하여 제동장치의 성능 기준 요구, 조명장치와 반사경 설치, 헬멧 착용 등의 개인안전 보장구 착용 의무 등을 규제하고 있다. 한국의 경우 2020년 2월부터 도로를 이용하는 교통수단으로써 
Table 2. International Safety Standards for Personal Mobility [5]

\begin{tabular}{|c|c|c|c|}
\hline Sortation & How to Pass & Performance Regulation & Safety standards \\
\hline Switzerland & Available on road/bicycle lanes & $\begin{array}{l}\text { Motor output: } 2 \mathrm{kw} \text { or less } \\
\text { Weight: } 200 \mathrm{~kg} \text { or less } \\
\text { Speed: } 20 \mathrm{~km} / \mathrm{h} \text { or less }\end{array}$ & - \\
\hline Sweden & Can not use the road & $\begin{array}{l}\text { Motor output: } 1 \mathrm{kw} \text { or less } \\
\text { Size: } 75 \mathrm{~cm} \times 160 \mathrm{~cm}\end{array}$ & $\begin{array}{l}\text { Brake: Deceleration } 3 \mathrm{~m} / \mathrm{s}^{2} \text {, parking } \\
\text { brake } \\
\text { Lighting device: Red rear light, } \\
\text { white/yellow light } \\
\text { Other devices: horn, steering system } \\
\text { personal safety gear: wearing a } \\
\text { helmet }\end{array}$ \\
\hline
\end{tabular}

\begin{tabular}{ll}
\hline & Motor output: $4 \mathrm{kw}$ or less \\
& Speed: $45 \mathrm{~km} / \mathrm{h}$ by city road, $30 \mathrm{~km} / \mathrm{h}$ \\
Netherlands Available on road/bicycle lanes & by bicycle road, $45 \mathrm{~km} / \mathrm{h}$ by bicycle Illumination: Reflectors, headlights \\
& road, $40 \mathrm{~km} / \mathrm{h}$ by bicycle road, \\
& Light Moped $2 \mathrm{~km} / \mathrm{h}$ \\
\hline
\end{tabular}

Germany Available on road/bicycle lanes Size: $70 \mathrm{~cm}$ wide

$\begin{array}{ll} & \\ \text { France } \quad \text { Bicycle lanes/walks available } \quad \begin{array}{l}\text { (In using the reports of six } \mathrm{km} \text {, not } \\ \text { more than } \mathrm{h} \text { ) less than at } 25 \mathrm{~km} \mathrm{~h} .\end{array}\end{array}$

\begin{tabular}{|c|c|c|c|}
\hline & & more than n) less than al $25 \mathrm{~km}$ n. & $\begin{array}{l}\text { (In using the bike lanes) hard hat, } \\
\text { vest. }\end{array}$ \\
\hline Australia & $\begin{array}{l}\text { (Queensland) Bicycle road/walk } \\
\text { available } \\
\text { Northern Territory) Shared path } \\
\text { available } \\
\text { (Others) Roads Not Available }\end{array}$ & - & $\begin{array}{l}\text { Lighting: Rear lights, headlights } \\
\text { Other devices: horn } \\
\text { Personal Safety Helmet: Bicycle } \\
\text { Safety Helmet }\end{array}$ \\
\hline U.S.A & $\begin{array}{l}\text { (Washington) Press unavailable } \\
\text { (New York) Highway/Bicycle } \\
\text { Road/Broadway Available } \\
\text { (California) Highway/Bicycle } \\
\text { Road/Broadway Available } \\
\text { (Others) Available }\end{array}$ & $\begin{array}{l}\text { Motor output: ( } 1 \text { wheel) } 0.75 \mathrm{kw} \\
\text { ( } 2 \text { wheels) } 2 \mathrm{kw} \\
\text { Speed below } 32 \mathrm{~km} / \mathrm{h} \\
\text { (roadway) not more than } 48 \mathrm{~km} / \mathrm{h} \text {; } \\
\text { (walk/bikeway) not more than } 88 \\
\mathrm{~km} / \mathrm{h} \text {; }\end{array}$ & $\begin{array}{l}\text { Personal Safety Equipment: Safety } \\
\text { helmet } \\
\text { Other devices: horn }\end{array}$ \\
\hline Singapore & Access to roads/bicycle roads/walks & $\begin{array}{l}\text { Weight: } 20 \mathrm{~kg} \text { or less } \\
\text { Speed: (road/bicycle road) } 25 \mathrm{~km} / \mathrm{h} \\
\text { (walk) } 15 \mathrm{~km} / \mathrm{h} \\
\text { Size: } 70 \mathrm{~cm} \text { wide }\end{array}$ & $\begin{array}{l}\text { Lighting device: Red rear light, } \\
\text { white light }\end{array}$ \\
\hline Japan & Bicycle lanes/walks available & $\begin{array}{l}\text { Motor output : kw } 1 \text { (approval of } \\
\text { two-wheeled) (other). } 6 \mathrm{kw} \\
\text { But not more than speed : } 10 \mathrm{~km} \mathrm{~h} \text {. }\end{array}$ & - \\
\hline
\end{tabular}
Lighting: Rear lights, headlights Other devices: horn

Vehicle Lighting Systems : lighting device (In using the bike lanes).

Individual Safety Equipments Using : (In using the bike lanes) hard hat,

Brake: Regulator and speed and limiter $\left(3.5 \mathrm{~m} / \mathrm{s}^{2}\right)$ required . 
필요한 최소한의 성능과 안전기준을 규제하고 있어, 안전 기준과 관련하여 어느 정도 국외와 비슷한 수준으로 규제 하고 있다고 보인다.

그러나 국내 기준과 비교하여 국외의 성능 기준 중 참 고되어야 할 사항은 속도 제한 규제로 보인다. 프랑스, 싱 가포르 등은 차도나 자전거 도로 이용시 자전거의 일반적 인 속도라고 알려진 $25 \mathrm{~km} / \mathrm{h}$ 이하 정도로 규제하고 있으 며, 불가피하게 보도를 이용해야 하는 경우 보행자의 보 행속도로 제한속도를 규제하고 있다. 프랑스의 경우 보행 속도인 $6 \mathrm{~km} / \mathrm{h}$ 로, 싱가포르의 경우 보행자의 달리기 속도 와 자전거를 여유롭게 타는 속도인 $15 \mathrm{~km} / \mathrm{h}$ 로 규제하고 있다. 이를 통해 보행공간 내 교통약자의 보행권을 고려 할 시 개인형 이동수단의 속도 규제가 필요할 것으로 보 이며, 이는 해당 공간과 구역을 함께 이용하는 교통약자 등의 속도 이하로 하는 것이 합리적이라 생각된다[5].

\section{개인형 이동수단에 대한 인식조사 분석}

\section{조사개요}

개인형 이동수단에 대한 시민들의 인식을 파악하기 위 해 설문조사를 실시하였다. 다만, 코로나 19로 인한 최근 의 사회적 거리두기 운동 등의 사회 여건상 직접 대면조사 가 어려워 'google form'을 활용한 온라인 설문을 실시하 였으며, 이용자는 크게 3 개 그룹(일반적인 보행자, 개인형 이동수단 이용자, 교통약자 등)으로 구분하여 200명을 대
상으로 실시하였다. 조사대상자 모집은 개인형 이동수단 이용자 커뮤니티 등의 홍보 및 교통약자 단체 등의 홍보 및 조사협조 요청을 통해 대상자를 모집하여 실시하였다 이용자는 네이버 카페(전타사, 자전거로 출퇴근하는 사람 들 등)의 공유킥보드 이용자를 대상으로 설문대상자를 모 집하여 실시하며, 그 외 교통약자와 전문가 등은 관련 교 통약자 단체 등의 추천을 통해 모집하였다.

조사는 2020년 7월 2일부터 7월 18일까지 17일 간 실 시하였으며, 설문지는 개인형 교통수단 이용자와 비이용자 를 구분하여 실시하였다. 총 207 개의 유효 설문지를 수집 하였으며, 분석은 SAS 9.4를 활용한 빈도분석 등을 실시 하여 개인형 이동수단에 대한 인식을 분석하였다. 주요 조 사 내용으로는 응답자 기본정보, 보행실태, 개인형 이동수 단에 대한 이해 및 보행공간 통행과 주차에 대한 인식, 새 로운 규제로 인한 보행권 확보 가능성에 대한 인식 등에 대한 내용을 중심으로 설문을 실시하였다.

\section{비이용자의 인식조사 결과}

개인형 이동수단 비이용자의 응답자 분포는 비장애인 $39.8 \%(66$ 명), 지체장애인 41.6\%(69명), 시각장애인 $8.4 \%$ (14명), 기타 장애 $10.2 \%(17$ 명)이었다. 연령별로 18 세 이 상 30 세 미만이 $25.9 \%(43$ 명), 30 세 이상 40 세 미만이 $25.9 \%(43$ 명), 40세 이상 65세 미만이 45.18\%(75명), 65 세 이상이 $0.6 \%(1$ 명)으로 대부분 청년과 중장년층이 응답 하였다.

Table 3. Survey Overview

\begin{tabular}{ll}
\hline Sortation & Content \\
\hline Date and time of investigation & July 2, 2020 -July 18, 2020 \\
\hline Investigation Method & Online survey using structured questionnaires (Google Form) \\
\hline Subject to investigation & $\begin{array}{l}\text { Ordinary citizens, the transportation disadvantaged, and users of personal } \\
\text { means of transportation }\end{array}$ \\
\hline
\end{tabular}

Table 4. Overview of non-users being interviewed

\begin{tabular}{|c|c|c|c|c|c|c|}
\hline Sortation & Content & & & & & \\
\hline \multirow{2}{*}{ Traffic Vulnerable Type } & Non-disabled & \multirow{2}{*}{\multicolumn{2}{|c|}{$\begin{array}{l}\text { the Handicapped } \\
41.57 \%(69)\end{array}$}} & \multirow{2}{*}{\multicolumn{2}{|c|}{$\begin{array}{l}\text { Blind } \\
8.43 \%(17)\end{array}$}} & \\
\hline & $39.76 \%(66)$ & & & & & $24 \%(17)$ \\
\hline \multirow{2}{*}{ Residence } & Seoul & \multirow{2}{*}{\multicolumn{3}{|c|}{$\begin{array}{l}\text { Gyeonggi Province } \\
27.71 \%(46)\end{array}$}} & \multirow{2}{*}{\multicolumn{2}{|c|}{$\begin{array}{l}\text { Etc } \\
11.45 \%(19)\end{array}$}} \\
\hline & $60.84 \%(101)$ & & & & & \\
\hline \multirow{2}{*}{ Age } & Under 18 & $18 \sim$ under 30 & \multicolumn{2}{|c|}{$30 \sim$ under 40} & $40 \sim$ under 65 & over 65 \\
\hline & $2.41 \%(4)$ & $25.9 \%(43)$ & \multicolumn{2}{|c|}{$25.9 \%(43)$} & $45.18 \%(75)$ & $0.6 \%(1)$ \\
\hline \multirow{2}{*}{ Gender } & Woman & \multicolumn{3}{|l|}{ Man } & \multicolumn{2}{|l|}{ Unresponsive } \\
\hline & $42.77 \%(71)$ & \multicolumn{2}{|c|}{$54.22 \%(90)$} & & \multicolumn{2}{|l|}{$3.01 \%(5)$} \\
\hline
\end{tabular}


주로 이용하는 교통수단에 관한 질문에 대하여 응답자 중 일상에서 주로 이용하는 교통수단은 개인승용자 $34.3 \%$ (57명), 지하철( $16.3 \%(45$ 명), 버스( $16.3 \%(27$ 명), 도보 $8.4 \%$ (14명) 순으로 응답하였다. 기타 응답의 경우 장애인 콜택 시 등 특별 교통수단 10 명, 전동스쿠터 1 명, 오토바이 1 명이었다.

보행자 공간의 안전상의 문제점에 대한 인식여부를 알 아보기 위한 질의에 대해 보행자 공간 안전성과 관련하여 문제가 있다고 응답한 비율은 $63.25 \%(105$ 명)이었으며,
교통약자 이동권과 관련되어 문제가 있다고 응답한 비율 은 $87.95 \%(146$ 명 $)$ 이었다.

개인형 이동수단 비이용자의 개인형 이동수단과 관련 한 필요 규제 사항에 대한 인식 결과는 다음과 같다. 비이 용자의 필요 규제 내용은 보행공간, 공원 광장 통행 금지 가 $35.14 \%(155$ 명 $)$ 이었으며, 헬멧 착용과 교통법규 준수 가 각 $21.77 \%(96$ 명), 운전면허 요구가 $17.91 \%(79$ 명)이었 다. 대부분의 비이용자는 보행자 공간에서의 개인형 이동 수단 통행 금지에 대한 규제가 필요하다고 응답하였다.

Table 5. Results of non-user perception surveys

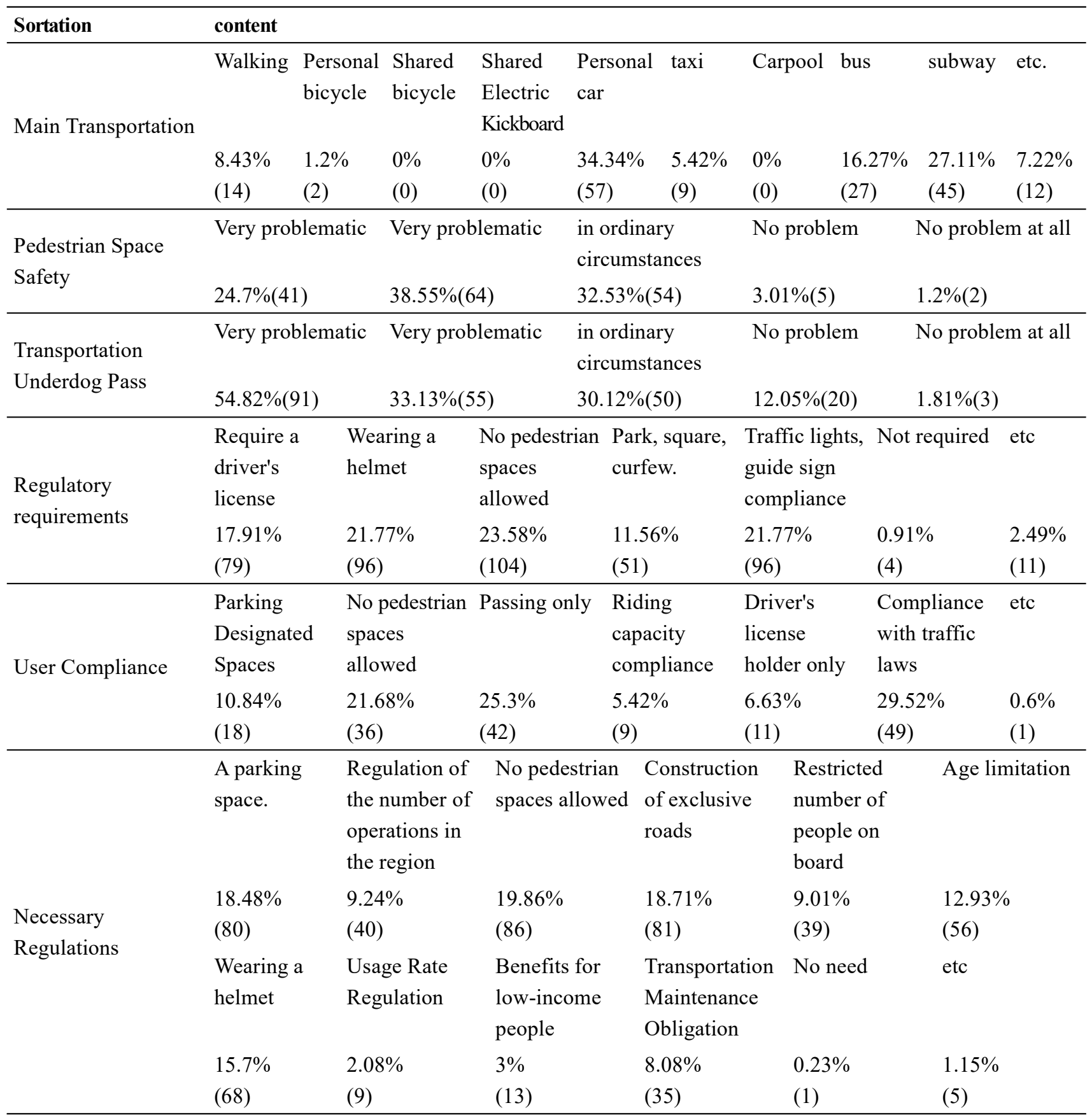


개인형 이동수단 이용자가 지켜야 하는 것 중 가장 중요 한 것에 대해서는 교통법규의 준수가 $29.52 \%(49$ 명), 지정 도로로만 통행이 $25.3 \%$ (42명), 보행공간 통행금지가 $21.7 \%$ (36명), 지정 공간에 주차가 $10.84 \%(18$ 명)으로 나타났다. 비 이용자는 개인형 이동수단 이용자의 교통법규 준수와 보 행공간 통행금지, 지정도로로만 통행을 가장 중요하게 여 기고 있는 것으로 나타났다.

개인형 이동수단과 관련된 새로운 기준을 만들 때 중요한 사항에 대한 인식은 보행공간 통행금지가 $19.9 \%(86$ 명), 적절한 전용도로의 제시 및 조성이 $18.7 \%(81$ 명 $)$, 적절한 위치에 주차가 $18.5 \%(80$ 명 $)$, 헬멧착용이 $15.7 \%(68$ 명 $)$, 이 용연령의 제한이 $12.9 \%(56$ 명) 순으로 응답하였다. 비이용 자는 새로운 규제 조성시 보행공간 통행 금지와 더불어 적절한 전용도로와 주차구역의 조성이 필요하다고 응답하 였으며, 안전을 고려하여 헬멧착용과 이용연령의 제한이 필요하다고 응답하였다.

\section{이용자의 인식조사 결과}

개인형 이동수단 이용자의 응답자 분포는 비장애인 $90.2 \%(37$ 명), 지체장애인 2.4\%(1명), 시각장애인 7.3\%(3 명) 이었다. 연령별로 18 세 이상 30세 미만이 39\%(16명), 30 세 이상 40 세 미만이 41.5\%(17명), 40세 이상 65 세 미 만이 $17.1 \%(7$ 명)으로 대부분 청년과 중장년층이 응답하 였다.

응답자 중 개인형 이동수단(전동 킥보드 등)의 이용목 적과 관련하여서 일상업무 연관(출퇴근, 업무시간 내 이동, 등하교 등)이 $36.6 \%(15$ 명 $)$, 여가와 놀이 목적 $29.3 \%(12$ 명), 그 외 일상적 외출이 $26.8 \%(11$ 명), 식당과 쇼핑이 각 $4.9 \%(2$ 명 $), 2.4 \%(1$ 명)로 조사되었다.

응답자 중 개인형 이동수단(전동 킥보드 등)의 이용 횟 수와 관련하여 주 4회 이상인 경우가 35\%(14명), 주 1 3 회가 $30 \%(12$ 명), 주 1회 미만이 25\%(10명)이었다.
개인형 공유이동수단 이용시 이용방법에 대한 교육 이 수 여부에 대해서는 $56.1 \%(23$ 명)가 안내문을 읽어보았 거나 교육을 받았다고 하였으며, $43.9 \%(18$ 명)는 안내문을 읽지 않았거나 별도 교육을 받지 않았다고 응답하였다. 이용방법 숙지 여부에 대해서는 '잘 알고 있음'이 $78.1 \%$ (32명), '잘 모름'이 22\%(9명)로 나타나 이용방법에 대해 이용자가 충분히 숙지하도록 할 필요가 있는 것으로 판단 된다.

개인형 이동수단 이용시 헬멧 착용 빈도와 관련하여서 는 $53.7 \%(22$ 명)가 거의 착용하지 않는다고 응답하여 이 용자 대부분 사고시 큰 부상 위험에 노출되어 있음을 알 수 있다.

개인형 공유 이동수단(전동 킥보드 등) 이용시의 어려 운 점에 대해서는 $45 \%(18$ 명)가 이용 가능한 전용도로의 부재, $20 \%(8$ 명 $)$ 가 안전성, $17.5 \%(7$ 명 $)$ 가 주차된 위치 찾 기 어렵다고 응답하였다.

개인형 공유 이동수단 이용시 문제에 대해서는 이동수 단의 방치와 무계획적인 주차가 $26.8 \%(11$ 명), 탑승정원 미준수 및 보행공간 주행이 각 $19.5 \%(8$ 명 $)$ 이라 응답하였 으며, 미성년자의 이용이 $9.8 \%(4$ 명 $)$, 그 외 기타가 $24.4 \%(10$ 명)이었다. 기타 응답의 경우 헬멧 미착용, 전용도로의 부 재, 서비스 지역의 한계, 기기 관리 및 장치에 대한 문제 등을 문제로 언급하였다.

개인형 공유 이동수단에 대한 새로운 규제 수립시 필 요한 부분에 대한 의견 조사 결과 적절한 위치나 공간에 거치 및 주차가 $14.9 \%(22$ 명 $)$ 으로 가장 많았으며, 탑승인 원 수의 제한, 이용연령 제한(운전면허 요구), 헬맷 착용 의무화가 각 $12.84 \%(19$ 명)이었다. 이와 더불어 적절한 전용도로의 제시 및 조성 필요하다는 응답이 $12.16 \%(18$ 명) 었으며, 이동수단에 대한 유지관리 의무부과, 보행공 간 주행금지 등에 대한 규제 필요성도 중요하다고 응답하 였다.

Table 6. Overview of users being interviewed

\begin{tabular}{|c|c|c|c|c|c|c|}
\hline Sortation & Content & & & & & \\
\hline \multirow{2}{*}{ Traffic Vulnerable Type } & non-disabled & \multicolumn{2}{|c|}{ the handicapped } & \multicolumn{2}{|c|}{ Blind } & Etc \\
\hline & $90.24 \%(37)$ & \multicolumn{2}{|c|}{$2.44 \%(1)$} & \multicolumn{2}{|c|}{$7.32 \%(3)$} & - \\
\hline \multirow{2}{*}{ Residence } & Seoul & \multicolumn{3}{|c|}{ Gyeonggi Province } & \multicolumn{2}{|c|}{ Etc } \\
\hline & $51.22 \%(21)$ & \multicolumn{2}{|c|}{$31.71 \%(13)$} & & \multicolumn{2}{|c|}{$17.07 \%(7)$} \\
\hline \multirow{2}{*}{ Age } & under 18 & $18 \sim$ under 30 & \multicolumn{2}{|c|}{$30 \sim$ under 40} & $40 \sim$ under 65 & over 65 \\
\hline & $2.44 \%(1)$ & $39.04 \%(16)$ & \multicolumn{2}{|c|}{$41.48 \%(17)$} & $17.08 \%(7)$ & - \\
\hline \multirow{2}{*}{ Gender } & Woman & \multicolumn{3}{|l|}{ Man } & \multicolumn{2}{|l|}{ Unresponsive } \\
\hline & $21.95 \%(9)$ & \multicolumn{2}{|c|}{$73.17 \%(30)$} & & \multicolumn{2}{|l|}{$4.88 \%(2)$} \\
\hline
\end{tabular}


Table 7. Results of user perception surveys

\begin{tabular}{|c|c|c|c|c|c|c|c|c|}
\hline \multirow{3}{*}{$\begin{array}{l}\text { Sortation } \\
\text { Means of transportation } \\
\text { Purpose of use }\end{array}$} & \multicolumn{8}{|l|}{ Content } \\
\hline & Daily operations & \multicolumn{2}{|c|}{ Leisure, play } & \multicolumn{2}{|c|}{ Restaurant } & \multicolumn{2}{|c|}{ Shopping } & etc \\
\hline & $36.59 \%(15)$ & \multicolumn{2}{|l|}{$29.27 \%(12)$} & \multicolumn{2}{|c|}{$4.88 \%(2)$} & \multicolumn{2}{|c|}{$2.44 \%(1)$} & $26.83 \%(11)$ \\
\hline \multirow{2}{*}{$\begin{array}{l}\text { Means of transportation } \\
\text { Number of times used }\end{array}$} & Every day & \multirow{2}{*}{$\begin{array}{l}\text { More than } \\
\text { once a day } \\
59 \%(2)\end{array}$} & \multirow{2}{*}{\multicolumn{2}{|c|}{$\begin{array}{l}4 \text { to } 6 \text { times a } \\
\text { week } \\
17.5 \%(7)\end{array}$}} & \multirow{2}{*}{\multicolumn{2}{|c|}{$\begin{array}{l}1 \text { to } 3 \text { times a } \\
\text { week } \\
30 \%(12)\end{array}$}} & $\begin{array}{l}\text { Less than } \\
\text { once a week }\end{array}$ & Experienced \\
\hline & $12.5 \%(5)$ & & & & & & $25 \%(10)$ & $10 \%(4)$ \\
\hline \multirow{2}{*}{ Trained how to use } & \multicolumn{4}{|c|}{ Trained (Read the guide) } & \multicolumn{4}{|c|}{ No training (no reading instructions) } \\
\hline & \multicolumn{4}{|l|}{$56.1 \%(23)$} & \multicolumn{4}{|c|}{$43.9 \%(18)$} \\
\hline \multirow{2}{*}{$\begin{array}{l}\text { Recognition of how to } \\
\text { use }\end{array}$} & \multicolumn{4}{|l|}{ Well-informed } & \multicolumn{4}{|l|}{ Not sure } \\
\hline & \multicolumn{4}{|l|}{$78.05 \%(32)$} & \multicolumn{4}{|c|}{$21.95 \%(9)$} \\
\hline \multirow{2}{*}{$\begin{array}{l}\text { When using } \\
\text { frequency of helmet } \\
\text { wearing }\end{array}$} & Not worn & \multirow{2}{*}{\multicolumn{2}{|c|}{ Almost Unworn }} & \multicolumn{2}{|c|}{$\begin{array}{l}\text { About half not } \\
\text { worn }\end{array}$} & \multicolumn{2}{|c|}{$\begin{array}{l}\text { Wear it } \\
\text { frequently }\end{array}$} & Always wear \\
\hline & $26.83 \%(11)$ & & & \multicolumn{2}{|c|}{$7.32 \%(3)$} & \multicolumn{2}{|c|}{$14.63 \%(6)$} & $24.39 \%(10)$ \\
\hline $\begin{array}{l}\text { Difficulties in using } \\
\text { personal shared } \\
\text { transportation }\end{array}$ & usage fee & $\begin{array}{l}\text { Difficult to } \mathrm{f} \\
\text { parking locat }\end{array}$ & & $\begin{array}{l}\text { Absence } \\
\text { available } \\
\text { roadway }\end{array}$ & & Lack & of safety & etc \\
\hline methods & $15.0 \%(6)$ & $17.5 \%(7)$ & & $45.0 \%(1$ & & $20.0 \%$ & o(8) & $2.5 \%(1)$ \\
\hline $\begin{array}{l}\text { means of } \\
\text { transportation } \\
\text { Problems when using }\end{array}$ & $\begin{array}{l}\text { Walkspace } \\
\text { Driving }\end{array}$ & Minors Use & & $\begin{array}{l}\text { Failure to } \\
\text { with boa } \\
\text { garden }\end{array}$ & $\begin{array}{l}\text { o comply } \\
\text { rding }\end{array}$ & $\begin{array}{l}\text { Leave } \\
\text { unatte } \\
\text { (unpla } \\
\text { parkir }\end{array}$ & $\begin{array}{l}\text { e vehicle } \\
\text { ended } \\
\text { anned } \\
\text { ng) }\end{array}$ & etc \\
\hline & $19.51 \%(8)$ & $9.76 \%(4)$ & & $19.51 \%($ & & 26.83 & $\%(11)$ & $24.39 \%(10)$ \\
\hline & $\begin{array}{l}\text { Parking in } \\
\text { appropriate } \\
\text { locations }\end{array}$ & $\begin{array}{l}\text { Limit number } \\
\text { of operations } \\
\text { in a given area }\end{array}$ & $\begin{array}{l}\text { Do } n \\
\text { in th } \\
\text { area }\end{array}$ & $\begin{array}{l}\text { ot drive } \\
\text { walking }\end{array}$ & $\begin{array}{l}\text { Provide/ } \\
\text { appropri } \\
\text { private } r\end{array}$ & $\begin{array}{l}\text { create } \\
\text { ate } \\
\text { oads }\end{array}$ & $\begin{array}{l}\text { Restricted } \\
\text { number of } \\
\text { people on } \\
\text { board }\end{array}$ & $\begin{array}{l}\text { Age limit } \\
\text { (license } \\
\text { requirement) }\end{array}$ \\
\hline & $14.86 \%(22)$ & $4.73 \%(7)$ & 7.43 & o(11) & $12.16 \%$ & 18) & $12.84 \%(19)$ & $12.84 \%(19)$ \\
\hline Regulatory Needs & $\begin{array}{l}\text { Wearing a } \\
\text { helmet }\end{array}$ & $\begin{array}{l}\text { Rate } \\
\text { Regulation }\end{array}$ & $\begin{array}{l}\text { Redi } \\
\text { exen } \\
\text { user } \\
\text { low- } \\
\text { earn }\end{array}$ & $\begin{array}{l}\text { ction or } \\
\text { ption of } \\
\text { fees for } \\
\text { ncome } \\
\text { rs }\end{array}$ & $\begin{array}{l}\text { Device } \\
\text { Mainten } \\
\text { Obligati }\end{array}$ & $\begin{array}{l}\text { ance } \\
\text { ns }\end{array}$ & Not required & etc \\
\hline & $12.84 \%(19)$ & $5.41 \%(8)$ & 0.68 & $0(1)$ & $8.78 \%(1$ & & $1.35 \%(2)$ & $6.08 \%(9)$ \\
\hline
\end{tabular}

\section{결론}

개인형 이동수단의 보행장애요소와 관련된 기존에 없 었던 새로운 이동수단에 대해서 기존의 제도로 관리하기 엔 한계가 존재한다. 향후 발전하는 사회에서 제도의 정 비는 항상 산업의 발전 속도를 따라가기엔 어려움이 존재 할 것이다. 이러한 상황에서 도시 공공의 영역에서 중요 한 요소 중 하나인 보행공간은 행정부 등 공공의 관리체
계 내에서 정비되고 관리되어야 하며, 유니버설한 보행환 경 조성을 위해 기본적인 원칙의 수립 후 적합한 제도의 정립이 필요하다. 이때 보행공간의 기본원칙은 보행공간 이 보행자를 위한 공간이며 보행속도가 느린 교통약자를 최우선으로 고려하여 제안되어야 할 것이다. 본 연구는 국내외 제도의 현황 고찰과 개인형 이동수단의 이용자 및 비이용자를 대상으로 한 인식조사를 통해 보행환경 개선 을 위한 방안을 도출하였으며, 제도적 개선을 위하여 아 
래의 세가지 원칙을 제안하고자 한다.

첫째, 보행공간을 개인형 이동수단이 이용할 경우에는 보행자의 보행속도 이하로 제한하여야 한다. 현행 최대속 도 $25 \mathrm{~km} / \mathrm{h}$ 이하고 제한하고 있는 경고문구 표시는 해외 의 사례와 같이 보행속도와 유사한 $6 \sim 15 \mathrm{~km} / \mathrm{h}$ 로 속도제한 을 규제할 필요가 있다.

둘째, 보행로 상의 보행장애물이 될 수 있는 개인형 이 동수단의 주차에 관해서는 별도의 장애물 구역에 설치하 거나, 보행로와 차로의 경계부에 위치하도록 한다. 해외 다수의 도시에서 개인형 공유 이동수단을 위한 지정 주차 구역 정책을 시행하고 있는 바 우리나라의 규정에도 명확 한 위치와 시설에 대한 기준을 제시할 필요가 있으며, 그 위치는 노외 주차공간과 같은 연석구간에 설정하고 스트 리트 퍼니처와 같은 정류소를 갖추거나 바닥면의 표시 등 을 하도록 하여야 할 것이다.

셋째, 보행공간은 공공의 영역으로 이의 사적 사용을 위해서는 이용요금을 부과하는 등 정당한 대가를 지불하 도록 한다. 지방정부에서는 개인형 이동수단의 주차를 연 석구간에 하는 경우 이동수단 기기당 일간 또는 월간 이 용 형태에 따라 이용요금을 부과할 필요가 있으며 일정 대수 이상의 이용과 주차가 되지 않도록 이동수단의 운영 대수를 조절하도록 규제할 필요가 있다.

이 외에도 개인형 이동수단의 이용방법에 대한 교육시 보행자의 안전을 고려하도록 교육내용을 강화하고 탑승인 원과 탑승연령을 제한하는 등의 제도개선이 요구된다.

\section{이해 충돌}

본 연구의 저자들은 연구, 저자권, 및 출판과 관련하여 잠재적인 이해충돌이 없음을 선언합니다.

\section{Acknowledgements}

본 논문은 2020년 서울시의회의 '개인형 이동수단 산 업의 확산에 따른 교통약자의 보행권 보장을 위한 개선방 안 모색' 연구의 일부를 재정리하여 작성함(ISBN 97911-6599-051-0)

\section{참고문헌}

1. Korea Internet Self-governance Organization Planning Team. Domestic Trends and Expected Effects of Scooter-sharing System. KISO Journal. 2019;36:31-6.

2. Urbanism next; University of Oregon. Shared Mobility Pilot Program Summary Report. Oregon (United States of America): Oregon University; 2019
3. San Francisco Municipal Transportation Agency. Powered Scooter Share Mid-Pilot Evaluation. California (United States of America); 2019.

4. Shaheen, S., Cohen, A., Randolph, M., Farrar, E., Davis, R., \& Nichols, A. Shared Mobility Policy Playbook. California: UC Berkeley; 2019.

5. Yu KS, Hong SY, Kim OS, Park SH. Strategies to Cope with the Spread of Personal Mobility. Seoul: Seoul Institute; 2018 